\title{
Health-Justice Partnerships: Innovation in service delivery to support mental health
}

\begin{tabular}{|r|l|}
\hline Journal: & Journal of Public Mental Health \\
\hline Manuscript ID & JPMH-03-2020-0018.R2 \\
\hline Manuscript Type: & Public Health Case Study \\
\hline Keywords: & $\begin{array}{l}\text { Social Welfare, Legal Services, Delivery of Health Care, Integrated, } \\
\text { Social Determinants of Health }\end{array}$ \\
\hline \multicolumn{2}{|l}{} \\
\hline
\end{tabular}

\section{SCHOLARONE \\ Manuscripts}




\begin{abstract}
Purpose - This paper introduces the concept of 'health-justice partnership' (HJP), the provision of legal assistance for social welfare issues in healthcare settings. It discusses the role of these partnerships in supporting health and care for people with mental health issues.

Design/methodology/approach - We describe an example of a health-justice partnership, discuss the rationale and evidence for this approach in relation to mental health, and reflect on implementation challenges and future directions in the UK. We draw on both health and legal literature to frame the discussion.
\end{abstract}

Findings - Social welfare legal needs have negative impacts on mental wellbeing and are more likely to occur among people with mental health conditions. Integrating legal assistance with healthcare services can improve access to support for those with unmet need. High quality research has demonstrated positive impacts for mental health and wellbeing as a result of HJP interventions. Both further research and wider strategies are required to support implementation of HJPs in practice.

Originality/value - Legal assistance is rarely positioned as a health intervention, yet it is an effective tool to address social welfare issues that are harmful to mental health and to which people experiencing mental health are at greater risk. This paper highlights the importance of the HJP movement as an approach for supporting mental health.

\title{
Social welfare legal problems and mental health
}

Social welfare law governs the rights of citizens in relation to issues such as welfare benefits, debt, housing, employment and community care. The conditions referred to as 'social determinants of health' often have their roots in social welfare legal issues; for example, poverty, homelessness, adverse living and working conditions. A wealth of literature documents the impacts of these social determinants on health and inequalities(e.g. Marmot et al., 2010, Marmot et al., 2020), however their legal underpinnings are rarely recognised in the public mental health discourse.

Unmet legal needs have a particularly strong relationship to mental health and wellbeing. Stressrelated illnesses or other adverse consequences for mental health are reported by a fifth of adults 
experiencing a legal problem(Franklyn et al., 2017). These health consequences can lead people to require and utilise healthcare services(Pleasence et al., 2008). The relationship between legal problems and health is bi-directional, with illness being one of the major factors leading to the development of social welfare legal problems such as issues with employment and eligibility for income support(Nosowska, 2004; Zevon et al., 2007). People with mental health issues tend to have more complex and urgent needs for legal advice(Mette and Williams, 2017) and more commonly report discrimination in relation to welfare benefits(Hamilton et al., 2016).

Legal assistance is an intervention that can be used to tackle mental health-harming social conditions and help prevent adverse social impacts of deterioration in mental health (Genn, 2019). Partnerships between healthcare and legal services have emerged across the world in response to these interconnected health and welfare needs(Lawton, 2014; Forell, 2018). In this paper we describe an example of a health-justice partnership, discuss the rationale and evidence for this approach in relation to mental health, and reflect on implementation challenges and future directions in the UK. We draw on both health and legal literature to frame the discussion.

\section{The health-justice partnership approach}

In England and Wales, the most common health-justice partnership service model is primary-care based welfare rights advice, where the advice service is co-located and/or receiving referrals from healthcare professionals(Beardon and Genn, 2018). One example of this type of partnership operated across two London boroughs until 2018, having begun around a decade before. The local Citizens Advice service ran appointments co-located in GP practices across the boroughs, to which patients could self-refer or be signposted by practice staff. Specialist advice and casework support was provided primarily for welfare benefits and debt, and generalist advice was offered on a broader range of welfare issues such as housing and employment. A diversity of other service models exists across the country, with legal assistance being integrated into a range of healthcare settings; this includes examples in secondary mental healthcare and community-wide mental health strategies(Beardon and Genn, 2018).

The co-located welfare advice in the London GP practices had various aims. On an individual level it aimed to reduce symptoms of anxiety, depression and stress associated with adverse social circumstances, by improving the accessibility of advice and increasing income. At a practice level, aims included to reduce GP consultations for social welfare legal issues and the anxiety linked to them; to reduce practice time spent on non-health issues; and to increase staff confidence in raising 


\section{Research on mental health impacts of health-justice partnerships}

Evidence of mental health improvements has largely been explored through qualitative studies, which have consistently identified positive impacts; for example reduced feelings of stress, anxiety and depression, greater peace of mind and reassurance, better sleeping patterns, improved quality of life and a sense of hope, empowerment, confidence and wellbeing(Moffatt et al., 2004, 2006, 2010; Moffatt and Scambler, 2008; Moffatt and Mackintosh, 2009; Burrows et al., 2011). However, translating these findings into quantitative evidence has proved a challenging task for researchers: robust comparator groups are difficult to generate for both practical and ethical reasons, and existing randomised controlled trials have been affected by poor intervention targeting, contamination between trial arms and loss to follow-up(Howel et al., 2019).

A study conducted in the London GP setting described above overcame these limitations: it successfully demonstrated significant improvements in mental health and wellbeing among people receiving welfare rights advice through their GP practices using a quasi-experimental design(Woodhead, et al., 2017b). Symptoms of common mental disorder and wellbeing scores were measured over a three month period before and after receipt of welfare rights advice. The 
comparison group was drawn from a community sample and analyses minimised selection bias through the use of propensity score weighting and a difference-in-difference approach. Compared to controls, the findings demonstrated significantly greater improvements in financial strain for the intervention group overall; in mental wellbeing among individuals whose situation improved as a result of advice; and, in rates of common mental disorders among women and Black participants. Improvements in stress levels since receipt of advice were also reported, with $26 \%$ of respondents in the intervention group reporting this outcome at follow-up.

\section{Implementation challenges}

In the time since the study in the London GP setting was conducted(Woodhead et al., 2017a,b), the Citizens Advice service in one of the boroughs where the research took place was decommissioned and no longer operates. The care navigation service it was replaced with provides no dedicated or specialist assistance for social welfare legal issues. This reflects the challenges for sustainability that health-justice partnerships commonly experience. In England and Wales, funding comes largely from charities and local authorities and much of it is short-term (Beardon and Genn, 2018). The turnover rate also seems to be high, with services breaking apart or closing down after a period of operation. Other challenges include developing effective systems for joining up care, achieving the engagement of healthcare staff, and embedding integrated ways of working into routine practice(Bateman, 2008; Gabbay et al., 2017; Woodhead et al., 2017a).

There are many factors that could be responsible for the success or failure of health-justice partnerships and these influences are currently not well understood. Cultural differences between health and legal sectors may play a part: professional relationships and attitudes are known to influence whether inter-professional working practices take root(Greasley and Small, 2005). Other factors such as management, governance and resourcing arrangements are also likely to be important (Sherr et al., 2002). To generate evidence on how health-justice partnerships can be implemented successfully, the authors are undertaking more in-depth research with services across England. This work will use a comparative case study approach to explore various service models and generate insights from different approaches, with the aim of supporting service delivery on the ground and informing strategy in the field more widely.

\section{Future directions in policy and practice}

Recent cuts to publically funded legal aid have significantly reduced access to free legal assistance for social welfare issues in England (Ministry of Justice, 2012) with disproportionate impacts on 


\section{References}

Amnesty International (2016) 'Cuts that Hurt: The impact of legal aid cuts in England on access to justice', Amnesty International UK. Available at: www.amnesty.org.uk/cutsthathurt.

Banks, J., Karjalainen, H., and Carol Propper, C. (2020) 'Recessions and health: The long-term health consequences of responses to coronavirus'. Institute for Fiscal Studies.

Barnes, M. C. et al. (2017) 'Seeking help in times of economic hardship: Access, experiences of services and unmet need', BMC Psychiatry, 17(84). doi: 10.1186/s12888-017-1235-0.

Bateman, N. (2008) 'Just what the doctor ordered: Welfare benefits advice and healthcare', Age Concern England.

Beardon, S. and Genn, H. (2018) 'The Health Justice Landscape in England and Wales: Social welfare legal services in health settings', UCL Centre for Access to Justice.

Burrows, J., Baxter, S., Baird, W., Hirst, J. and Goyder, E. (2011) 'Citizens advice in primary care: A qualitative study of the views and experiences of service users and staff', Public Health, 125, pp. 704-710. doi: 10.1016/j.puhe.2011.07.002.

Cheetham, M., Moffatt, S., Addison, M. and Wiseman, A. (2019) 'Impact of Universal Credit in North East England: A qualitative study of claimants and support staff', BMJ Open, 9(e029611). doi: 10.1136/bmjopen-2019-029611.

Forell, S. (2018) 'Mapping a new path: The health justice landscape in Australia, 2017', Health Justice Australia.

Franklyn, R., Budd, T., Verrill, R. and Willoughby, M. (2017) 'Findings from the Legal Problem and Resolution Survey, 2014-15', Ministry of Justice.

Gabbay, M. et al (2017) 'Debt Counselling for Depression in Primary Care: an adaptive randomised controlled pilot trial (DeCoDer study)', Health Technology Assessment, 21(35) doi: 10.3310/hta21350. 
Galvin, K., Sharples, A. and Jackson, D. (2000) 'Citizens Advice Bureaux in general practice: an illuminative evaluation', Health and Social Care in the Community, 8(4), pp. 277-282.

Genn, H. (2019) 'When Law is Good for Your Health: Mitigating the Social Determinants of Health through Access to Justice', Current Legal Problems, 72(1), pp. 159-202. doi: 10.1093/clp/cuz003.

Greasley, P. and Small, N. (2005) 'Establishing a welfare advice service in family practices: Views of advice workers and primary care staff', Family Practice, 22, pp. 513-519. doi:

10.1093/fampra/cmi047.

Hamilton, S. et al. (2016) 'Qualitative analysis of mental health service users' reported experiences of discrimination', Acta Psychiatrica Scandinavica, 134, pp. 14-22. doi: 10.1111/acps.12611.

Howel, D. et al. (2019) 'Does domiciliary welfare rights advice improve health-related quality of life in independent-living, socio-economically disadvantaged people aged 60 years? Randomised controlled trial, economic and process evaluations in the North East of England', PLOS ONE, 14(1). doi: 10.1371/journal.pone.0209560.

Hudson-Sharp, N., Munro-Lott, N., Rolfe, H. and Runge, J. (2018) 'The impact of welfare reform and welfare-to-work programmes: an evidence review', Equality and Human Rights Commission.

Kite, A. (2016) 'Citizens Advice in GP surgeries', University of Bristol Law School.

Kousoulis, A., Van Bortel, T., Hernandez, P. and John, A. (2020) 'The long term mental health impact of covid-19 must not be ignored'. BMJ Opinion. Available from:

https://blogs.bmj.com/bmj/2020/05/05/the-long-term-mental-health-impact-of-covid-19-must-notbe-ignored/.

Lawton, E. (2014) 'A History of the Medical Legal Partnership Movement', Community Health Forum.

London Health Forum (2009) 'London: capital of debt - Reducing the health consequences of personal debt', The London Health Forum.

Marmot, M. et al. (2010) 'Fair Society, Health Lives', Institute of Health Equity.

Marmot, M., Allen, J., Boyce, T., Goldblatt, P. and Morrison, J. (2020) 'Health equity in England: The Marmot Review 10 years on', Institute of Health Equity.

Mette, I. and Williams, R. (2017) 'Joining the dots: Integrating practical support in mental healthcare settings in England', Citizens Advice.

Ministry of Justice (2012) 'Legal Aid, Sentencing and Punishment of Offenders Act'. Government of the United Kingdom.

Moffatt, S., White, M., Stacey, R., Downey, D. and Hudson, E. (2004) 'The impact of welfare advice in primary care: a qualitative study', Critical Public Health, 14(3), pp. 295-309. doi: 10.1080/09581590400007959.

Moffatt, S., Mackintosh, J., White, M., Howel, D. and Sandell, A. (2006) 'The acceptability and impact of a randomised controlled trial of welfare rights advice accessed via primary health care: Qualitative study', BMC Public Health, 6, p. 163. doi: 10.1186/1471-2458-6-163.

Moffatt, S. et al. (2016) 'A qualitative study of the impact of the UK "bedroom tax"', Journal of Public Health. Oxford University Press, 38(2), pp. 197-205. doi: 10.1093/pubmed/fdv031.

Moffatt, S. and Mackintosh, J. (2009) 'Older people's experience of proactive welfare rights advice: Qualitative study of a South Asian community', Ethnicity and Health, 14(1), pp. 5-25. doi: 10.1080/13557850802056455. 
Moffatt, S., Noble, E. and Exley, C. (2010) "Done more for me in a fortnight than anybody done in all me life." How welfare rights advice can help people with cancer', BMC Health Services Research, 10(1), p. 259.

Moffatt, S. and Scambler, G. (2008) 'Can welfare-rights advice targeted at older people reduce social exclusion?', Ageing and Society, 28, pp. 875-899. doi: 10.1017/S0144686X08007253.

Nosowska, G. (2004) 'A delay they can ill afford: Delays in obtaining attendance allowance for older, terminally ill cancer patients, and the role of health and social care professionals in reducing them', Health and Social Care in the Community, 12(4), pp. 283-287. doi: 10.1111/j.13652524.2004.00496.x.

Pereira, I., Perry, C., Greevy, H., and Shrimpton, H. (2015) 'The Varying Paths to Justice: Mapping problem resolution routes for users and non-users of the civil, administrative and family justice systems', Ministry of Justice, ISBN 978-1-84099-726-2.

Pleasence, P., Balmer, N. J. and Buck, A. (2008) 'The Health Cost of Civil-Law Problems: Further Evidence of Links Between Civil-Law Problems and Morbidity, and the Consequential Use of Health Services', Journal of Empirical Legal Studies, 5(2), pp. 351-373.

Sherr, L., Sherr, A,. Harding, R., Moorhead, R., and Singh, S. (2002) A stitch in time: Accessing and funding welfare rights through Health Service Primary Care. University of London.

Sherratt, M., Jones, K. and Middleton, P. (2000) 'A citizens' advice service in primary care: Improving patient access to benefits', Primary Health Care Research and Development, 1, pp. 139-146. doi: 10.1191/146342300672823063.

Wickham, S. et al. (2020) 'Effects on mental health of a UK welfare reform, Universal Credit: a longitudinal controlled study', The Lancet Public Health, 5(3), pp. e157-e164. doi: 10.1016/S24682667(20)30026-8.

Woodhead, C., Collins, H., Lomas, R. and Raine, R. (2017a) 'Co-located welfare advice in general practice: A realist qualitative study', Health and Social Care in the Community, 25(1794-1804), pp. 1794-1804. doi: 10.1111/hsc.12453.

Woodhead, C., Khondoker, M., Lomas, R. and Raine, R. (2017b) 'Impact of co-located welfare advice in healthcare settings: prospective quasi-experimental controlled study', The British Journal of Psychiatry, 211(6), pp. 388-395. doi: 10.1192/bjp.bp.117.202713.

Zevon, M., Schwabish, S., Donnelly, J. and Rodabaugh, K. (2007) 'Medically related legal needs and quality of life in cancer care: A structural analysis', Cancer, 109(12), pp. 2600-2606. doi: $10.1002 /$ cncr.22682. 